\title{
DIGITAL PIONEERS: COMPUTER-GENERATED ART FROM THE V\&A'S COLLECTIONS
}

\author{
Douglas Dodds \\ Senior Curator, Word \& Image Department \\ Victoria and Albert Museum
}

The Victoria and Albert's acquisition of major computer art collections is part of an ongoing project to document and preserve the history of this field. The V\&A's pioneering work in this area is connected to the Computer Art and Technocultures project, in collaboration with Birkbeck College.

\section{INTRODUCTION}

The Victoria and Albert Museum is one of the world's leading museums of art and design. The V\&A's Word and Image Department holds the Museum's Western collections of prints, drawings, paintings and photographs, plus books, archives and manuscripts. The Department has more than 2 million objects in total, including some 750,000 prints, drawings and paintings and a similar number of printed books. Any works that are not on loan or display can be consulted in the Museum's Prints and Drawings Study Room or the National Art Library.

The V\&A is currently engaged in a research project with Birkbeck, entitled Computer Art and Technocultures and funded by the UK's Arts and Humanities Research Council. One of the outcomes is this symposium and another is Digital Pioneers, a book and associated display based upon the Museum's computer-generated art and design collections. The following sections provide more details about the Museum's collections, the project and the display.

\section{THE V\&A'S COMPUTER-RELATED ART COLLECTIONS}

In a review entitled Notes on the crisis in technological art, Gustav Metzger produced a thoughtful and highly prescient commentary on an early exhibition organised by the Computer Arts Society. In a section entitled The Art World, he writes:

It is impossible for the museum and commercial gallery structure to accomodate [sic] the volume of art that will be produced in the next few decades. It is therefore vital to begin developing new structures that will enable these new works to be produced and exhibited. .. Dealers and museums see to it that there is the minimum of technological advance, since they cannot afford the expense of advanced technologies, they are faced by new and complex problems of installing advanced works... [1] 


\section{CAT 2010 London Conference $\sim 3^{\text {rd }}$ February \\ Douglas Dodds}

It is certainly true that most - if not all - museums and galleries have struggled to come to terms with digital methods of making art. Nevertheless, the V\&A has been collecting computer-generated artworks from the late 1960s onwards, at around the time when Metzger was writing about the challenges involved. Some of the Museum's earliest acquisitions were a series of prints produced in conjunction with Cybernetic Serendipity, the groundbreaking exhibition at the Institute of Contemporary Arts in 1968. The V\&A's Prints, Drawings and Paintings Department (as it was then called) went on to collect other works by computer artists during the 1970s and 80s, but these were few and far between. Notable examples include a number of prints by Manfred Mohr, from his Scratch Code series. At the time, computer art was seen to be deeply unfashionable among many art historians and commentators, and the V\&A's curators were probably influenced by this attitude. In hindsight, it seems fair to say that many of them did not anticipate the full significance of the emerging medium. They were also understandably concerned that the original material - plotter drawings, computer printouts, or whatever - might be difficult to preserve and display.

Until recently, though, the Museum held relatively few works that illustrate the early years of computer-generated art and design. However, following the acquisition of the Patric Prince Collection and the archives of the Computer Arts Society, the V\&A now holds an internationally significant collection of computer-generated art from the 1960s to the 1990s and beyond. Practitioners represented in the Museum's holdings include Paul Brown, Harold Cohen, Charles Csuri, David Em, Herbert Franke, Jean-Pierre Hébert, D.P. Henry, Ken Knowlton, Tony Longson, Manfred Mohr, Vera Molnar, Frieder Nake, Georg Nees, Barbara Nessim, Michael Noll, Lillian Schwartz, Roman Verostko and Mark Wilson, among many others. The bulk of the artworks consist of plotter drawings, screen prints, inkjet prints, posters and photographs, but there are also examples in other media, including 3D images and computer files.

The founding-stone of the V\&A's expanding collection is the material assembled by Patric Prince, an art historian and archivist of computer art. Based in California, Patric actively collected computer-assisted art works for many years. In addition to some 200 individual artworks, the Patric Prince collection also contains a huge quantity of books, archival material and ephemera, including monographs, manuals, exhibition catalogues, slides, off-prints and interviews with practising artists. Because the early history of digital culture is still under-documented, the material she accumulated is now of great significance to researchers.

In addition to the Patric Prince collection, the Museum also holds the archives of the Computer Arts Society (CAS)[2], which amounts to another 200 artworks. As computer artists passed through London, they often gave the Society examples of their work. These were stored until the V\&A acquired the collection in 2007, along with the 
CAT 2010 London Conference $\sim 3^{\text {rd }}$ February
Douglas Dodds

Society's working records of its own activities. Thankfully, the CAS material complements the Patric Prince collection perfectly, with very little overlap between the two. Together, these major acquisitions have formed the basis for the V\&A's emerging national collection of computer-generated art.

Inevitably, the fact that the Museum is now known to be collecting in this area has already resulted in the offer of additional material, from the early 1960s onwards. Indeed, the founding collections have recently been supplemented by a number of other donations and individual acquisitions that have significantly expanded the range and quality of the V\&A's holdings. In practice, though, we need to ensure that anything we do acquire is of museum quality and fits the profile of the V\&A's collections. For example, we would be reluctant to acquire works that document the early years of computer-generated music, other than where these clearly inform the early years of computer art. Similarly, the V\&A does not generally collect contemporary sculpture, so we would be reluctant to acquire too many three- dimensional works.

Nevertheless, the Museum has actually acquired relatively few born-digital works for its permanent collection until now. Instead, in recent years we have commissioned a number of temporary exhibitions and installations that have provided a showcase for digital artists. The V\&A's Contemporary programme, in particular, has been responsible for displaying a wide range of innovative works. Examples include Digital $>$ Responses (2002-3), in which artists created works in response to objects and spaces in the V\&A; Volume (2006-7), a luminous interactive installation in the Museum's John Madejski Garden; plus many Friday late-night events on specific themes.

\section{THE COMPUTER ART AND TECHNOCULTURES PROJECT}

When the V\&A first began to acquire the Patric Prince collection, we were conscious that we needed to acquire more resources in order to make it fully accessible. Given Birkbeck's previous involvement in the CACHe project, it made sense to build upon the strengths of the two institutions. The project was therefore conceived as a joint study between the School of History of Art, Film \& Visual Media at Birkbeck and the V\&A's Word \& Image Department. A bid was submitted to the Arts and Humanities Research Council's Resource Enhancement Scheme, and in July 2007 we finally learnt that we had been awarded the full amount requested.

The aim of Computer Art and Technocultures (CAT) is to study the development of computer-based art during the expansion of digital graphics techniques that occurred in the US and worldwide from the 1970s onwards. Although the computer is now so widely used in the applied and fine arts, the origins of computational artwork have not been much explored until very recently, when historians of "Media Art" started to turn their attention to this field. The initial CACHe Project (2002-2006) was one result of this new interest in the history of the digital arts. 


\section{CAT 2010 London Conference $\sim 3^{\text {rd }}$ February \\ Douglas Dodds}

The CAT project team consists of Dr Nick Lambert, Professor Jeremy Gardiner and Francesca Franco at Birkbeck, plus Douglas Dodds and Honor Beddard at the V\&A. The project uses the Patric Prince collection as the basis for the team's research, but it also draws on information obtained from the rest of the V\&A's computer art collections, plus the earlier CACHe project and other resources elsewhere.

\section{DOCUMENTING THE COMPUTER ART COLLECTION}

The Museum is currently cataloguing the entire collection and digitising the artworks wherever possible. The sheer range of material presents particular challenges, since the collection includes artworks, publications and Patric Prince's own records. The curatorial objects are being described in the V\&A's Collections Information System (CIS), and are becoming available on the Museum's website via a service known as Search the Collections. The vast majority of books have now been catalogued on the National Art Library's computer system and are now included in the library's online catalogue. The archival parts of the collection are being listed using Encoded Archival Description (EAD), an XML schema used by many archivists. The digital images are stored in the Museum's digital asset management system, VADAR. In addition, the V\&A's website now includes a section dedicated to computer art, with zoomable images and brief biographies of some artists.

The V\&A has recently re-launched its Search the Collections database, which now includes more than a million records for objects in the Museum's collections. The amount of information varies from record to record, and the Word \& Department is currently engaged in a project to create detailed descriptions and digital images for all of its holdings. As a result of work undertaken via the Computer Art and Technocultures project, a high proportion of the computer art collections are already included in the database and are fully accessible. Search the Collections is available via the Museum's website and can also be accessed directly . [3]

As an additional outcome of the project, the V\&A has recently published a picture book entitled Digital Pioneers. This forms part of a highly-affordable series of books on pattern in the V\&A's collections. As such, computer-generated art has been absorbed into the mainstream, alongside other topics in the series, such as William Morris, The Fifties, and Indian floral textiles. The first four books in the series - including Digital Pioneers - are also available as a limited-edition boxed set. [4]

In parallel, Nick Lambert and his colleagues at Birkbeck are constructing a critical and contextual history of this under-explored area of the visual arts. The research undertaken by Birkbeck is also helping to inform and enhance the records created by the V\&A. For more information, see the project website at:

http://www.technocultures.org.uk 


\section{CAT 2010 London Conference $\sim 3^{\text {rd }}$ February \\ Douglas Dodds}
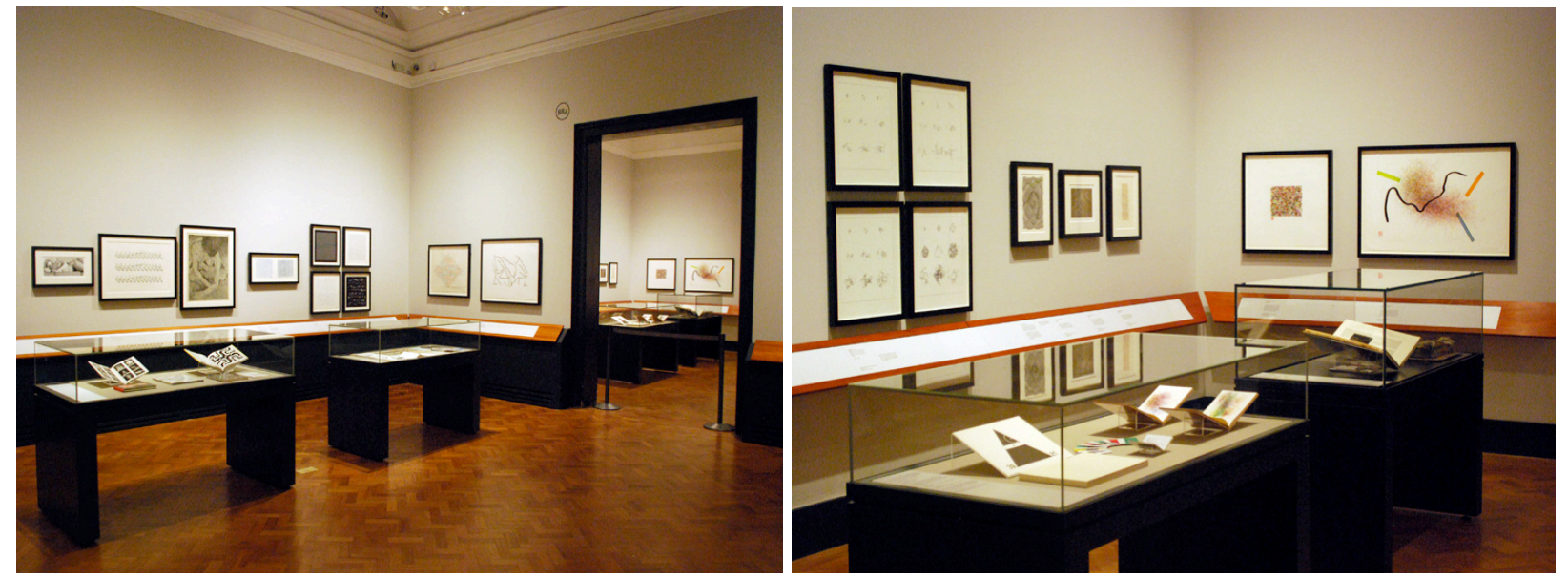

\section{DECODE AND THE DIGITAL PIONEERS DISPLAY}

Some time after Birkbeck and the V\&A were awarded the grant from the Arts and Humanities Research Council, it became clear that the V\&A's Contemporary team were planning to organise a major exhibition called Decode: Digital Design Sensations. Curated in collaboration with the leading digital arts organisation onedotzero, the Decode exhibition opened in December and continues until April 2010. Highly interactive and technologically driven, it sets out to demonstrate some of the latest developments in digital design, from small screen based graphics to large-scale installations. The show includes works by Daniel Brown, Simon Heijdens, Aaron Koblin, Golan Levin, John Maeda, Random International, Casey Reas, Daniel Rosin and Troika, among others. The exhibition explores three main themes: Code as a Raw Material, Interactivity, and the Network. Most of the exhibits are on show in the Museum's Porter Gallery, but there are also installations in the main entrance, the garden, the sculpture galleries and the exterior of the building itself.

In conjunction with Decode, the Computer Art and Technocultures partners have organised an "historic" counterpart, entitled Digital Pioneers. This display is one of the outcomes of the CAT project, and is designed to provide an overview of the first decades of the computer's history in art and design. It includes some of the earliest computer-generated works in the V\&A's collections, many of which have never been exhibited in the UK before. Digital Pioneers seeks to offer a historical context for contemporary digital practice, and has been deliberately scheduled to coincide with Decode.

Museums such as the V\&A generally make distinctions between exhibitions, which contain works borrowed from elsewhere, and displays, which consist of works from the institution's own collections. All of the works in Decode have been borrowed for the 
duration of the exhibition, though the Museum is actively considering acquiring some pieces for its permanent collection. In contrast, Digital Pioneers consists purely of works from the V\&A's own holdings, including objects donated by Patric Prince and the Computer Arts Society. The artworks in Digital Pioneers are organised chronologically, and in broad groupings. The first section is entitled From Analogue to Digital, and begins with two early "Oscillons" by Ben Laposky. It also includes a number of analogue works by Herbert Franke and D.P. Henry, who used modified analogue bombsight computers to create highly distinctive machine drawings.

The second section, Early Practitioners, begins with digital works by Herbert Franke and Georg Nees, followed by additional algorithmic works by Frieder Nake, such as Homage to Paul Klee (1965). Other works in this section include Charles Csuri's Flies (1967) and his Random War (1967), which contains iconic images of American toy soldiers. Another famous work, Ken Knowlton and Leon Harmon's Study in perception (1967), is represented by a recent laser print. (The V\&A also holds an early photographic print of this, but the image is inexplicably reversed.) Knowlton also collaborated with Lillian Schwartz, one of a number of pioneering women in the show.

The third section, The Artist as Programmer, begins with Vera Molnar, who started to use computers in 1968. The Museum holds a number of early works by Manfred Mohr, who has spent much of his artistic life examining the possibilities presented by the cube. In the display, Mohr is represented by four prints from his Scratch Code series. The author of the Aaron computer program, Harold Cohen, is represented by no less than six early works, including two hand-coloured computer printouts that precede his Aaron program. Another significant British-born artist, Paul Brown, makes extensive use of tiling and cellular automata.

The last section, Computer Art after 1980, begins with three delicate computer drawings by Jean-Pierre Hébert, who has said that the creative process he uses is "very much akin to composing or choreographing, or simply ... thinking'. Another artist who makes extensive use of his own software, Roman Verostko, is represented by four unique plotter drawings from the 1980s onwards, including some that incorporate large plotter-driven brushstrokes produced on a modified pen plotter. In 1995 Hébert and Verostko began describing themselves as "Algorists"- artists who employ original algorithms in the process of creating their art. Verostko's plotter drawings are followed by two large works by Mark Wilson, who had also used pen plotters in his earlier work. More recently, Wilson switched to using large format inkjet printers to produce highly complex multi-layered abstract images such as the two included here. The wall display ends with Dark Filament (2007), a recent work by James Faure Walker, who marks the beginning of the following wave of artists who make extensive use of "paint" programs in their work. 


\section{CAT 2010 London Conference $\sim 3^{\text {rd }}$ February Douglas Dodds}

Digital Pioneers also includes a number of early publications, shown in broadly chronological order and starting with the catalogue of a touring exhibition of Laposky's Oscillons (1952-3). Other exhibitions include Cybernetic Serendipity and MOMA's The Machine as seen at the end of the mechanical age, both undertaken in 1968. The display also attempts to make pointers to other important organisations and events. Examples include the Computer Arts Society's Page magazine, plus a variety of SIGGRAPH ephemera collected by Patric Prince. Artists' books include Barbara Nessim's Random Access Memories (1991) and two copies of Roman Verostko's limited edition of George Boole's Derivation of the laws (1990), with unique plotter drawings and single brush strokes created using the same algorithm. The display's four desk cases end with William Gibson and Denis Ashbaugh's Agrippa (1992), which contains a selfdestructing floppy disk that echoes Gustav Metzger's concept of auto-destructive art. The text of Gibson's self-destructing poem was subsequently published on the emerging Internet, in an early example of subversive use of the online medium.

\section{CONCLUSIONS}

The Computer Art and Technocultures project has proved to be highly influential in helping to increase awareness of the significance of early computer-generated art. Many of the promised outcomes have now been completed, or are well on the way to being achieved. In addition, the project has also resulted in additional acquisitions that will enable the V\&A to undertake major exhibitions and displays in future years. Digital Pioneers presents an overview, but there is real scope for additional detailed examination in specific areas such as illustration or computer aided design.

\section{ACKNOWLEDGEMENTS}

With thanks to Honor Beddard at the V\&A; Nick Lambert, Jeremy Gardiner and Francesca Franco at Birkbeck; and the Arts and Humanities Research Council for its generous support for the project.

\section{BIOGRAPHY}

Douglas Dodds is a Senior Curator in the Victoria and Albert Museum's Word \& Image Department. He is also the Co-investigator in the AHRC-funded Computer Art and Technocultures project.

References

[1] METZGER, GUSTAV: "Notes on the crisis in technological art." Unpublished typescript sheet, 1969

[2] The Computer Arts Society's website is at: http://www.computer-arts-society.org/

[3] The V\&A's website is at http://www.vam.ac.uk. The Search the Collections database is also available directly at http://collections.vam.ac.uk

[4] BEDDARD, HONOR \& DODDS, DOUGLAS: Digital Pioneers. (London: V\&A, 2009) 